\title{
Las adaptaciones cinematográficas de la obra de José Echegaray. El gran galeoto (Rafael Gil, 1951)
}

institucional.us.es/ambitos/

\section{Juan Ignacio Valenzuela Moreno}

Universidad de Córdoba

alleong75@hotmail.com

English Version: Film adaptations of José Echegaray's work. El Gran Galeoto (Rafael Gil, 1951).

\section{Resumen}

La obra de José Echegaray no ha conocido una fecunda traslación al cine, ni en los inicios de este arte, ni, en lo que concierne al cine español, durante la dictadura

franquista, cuya figura, primer Premio Nobel que recibía un español, era tan respetada. Sí concitó cierto interés durante el cine mudo, donde cabe reseñar las producciones de José Buchs y las adaptaciones de El gran galeoto filmadas en Hollywood. Una de estas películas, Lovers, sirvió de pretexto a Rafael Gil para filmar una nueva versión, donde a la evidente rémora teatral antepuso una cuidada técnica y una sobria realización.

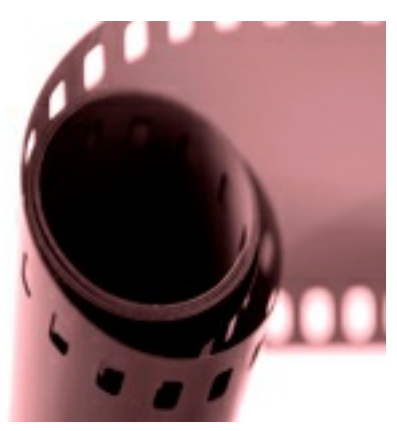

\section{Palabras clave}

José Echegaray, cine mudo, El gran galeoto, adaptaciones, Rafael Gil.

\section{Abstract}

The work of José Echegaray has not known a fruitful translation to the movies, at the beginning of this art, even in regard Spanish cinema, during the Franco dictatorship, whose figure, first Spanish Nobel Prize, was so respected. Echegaray attracted some interest during the silent film, where José Buchs' films and El gran galeoto's Hollywood adaptations stand out among everyone. One of these movies, Lovers, served as a pretext to Rafael Gil to film a new version, where he put ahead of the obvious theatrical impediment a maintained technique and a sober direction.

Keywords José Echegaray, silent cinema, El gran galeoto, adaptations, Rafael Gil.

\section{INTRODUCCIÓN}

En nuestro hábitat cultural, las celebraciones de nacimientos o fallecimientos son ocasiones inmejorables para hacer salir a la palestra figuras olvidadas o apartadas de la memoria colectiva $y$, aunque motivaciones injustas, se erigen en importantes trampolines para recordar, relanzar o

ÁMBITOS restituir la vida y obra de un insigne personaje que, de otra forma, quedarían sumidas en el más cruel olvido (la intención más loable sería, a partir de ese recuerdo, sobrevivir a la simple efeméride). El 14 de septiembre de 2016 se conmemora el centenario del fallecimiento de José Echegaray, una figura respetadísima en su tiempo (aunque fueran no pocos sus detractores), político implicado en el enaltecimiento de su país, matemático ilustre - faceta ésta que ha quedado relegada en su estudio, aun siendo de una importancia manifiesta - y dramaturgo de éxito, que veía cómo sus obras triunfaban no solo en la escena española, sino que se representaban en las tablas de medio mundo, con el corolario de ser el primer Premio Nobel español, de Literatura, obtenido ex aequo junto al poeta provenzal Frédéric Mistral. Pero un siglo después, su legado, su obra, se disuelve entre las oscuras brumas de la desmemoria. Casi permanece como un dato, como miembro de la selecta nómina de aquellos que han recibido el Premio Nobel, pues la estela de su obra ha llegado muy difusa hasta nuestros días. Quizá sea por esta razón que su nombre se resiste a abandonar una Historia de la 
Literatura Española, que ha condenado al ostracismo a dramaturgos coetáneos como Joaquín Dicenta, Pedro Marquina, Pelayo del Castillo o Pedro Escamilla.

En el último tercio del siglo XIX y en los albores del XX, cada estreno de una obra de Echegaray suponía de por sí todo un acontecimiento para los miembros de la alta burguesía que asistían con frecuencia al teatro. Aunque llegó a la literatura por razones más crematísticas que vocacionales (su forzado exilio en París huyendo de las revueltas posteriores a la abdicación de Amadeo I de Saboya, cuya llegada a la Monarquía hispana había patrocinado, le impulsó a escribir para la escena, intuyendo - equivocadamente - que su periplo político había concluido), su éxito, debido entre otros factores al carácter público que a la sazón tenía su figura y al indudable prestigio de los intérpretes que representaron sus creaciones (María Guerrero, de la que fue íntimo amigo, Ricardo Calvo o Antonio Vico) fue inmediato entre el público. No existió, sin embargo, una uniformidad crítica hacia su obra: si Emilia Pardo Bazán o Leopoldo Alas Clarín fueron ambiguos en su consideración hacia el dramaturgo madrileño, peor estimación tuvo en la "Generación del 98", algunos de cuyos miembros, como Valle-Inclán o Azorín, firmaron un manifiesto en el que mostraron su disconformidad con la concesión del Premio Nobel. En el extranjero, por el contrario, el arrollador éxito de El gran galeoto (1881) le granjeó grandes simpatías en reconocidos autores como Henry Ibsen, Pirandello o George Bernard Shaw, que a la postre serían determinantes en la obtención del prestigioso galardón sueco.

Integrante de lo que se ha dado en llamar el posromanticismo español - Emilia Pardo Bazán calificó a Echegaray de «rezagado del romanticismo» (Echegaray, 1959: 28) -, se ha tachado al dramaturgo de excesivamente retórico, muy sujeto a la declamación y al talento de los actores, rimbombante en el diálogo y repleto de ringorrangos. Aunque resaltaba temas universales como la envidia, el arribismo, la maledicencia, la injusticia o las pasiones amorosas, el estilo grandilocuente de su teatro y el desborde pasional de sus personajes, marcadamente antinatural, le condenó a encadenarse a su tiempo. Joan Mañé i Flaquer calificó sus obras de «melodramas trasnochados, puestos en verso por un retórico» (Mesonero Romanos, 2008: 258). Muy al contrario de lo que ocurriría con Jacinto Benavente - quien acabaría tomando el testigo de Echegaray en el favoritismo del público burgués de la escena española -, que opta por abandonar el decadente posromanticismo, al tiempo que se acercaría tímidamente al teatro producido en Europa hasta la eclosión de los ismos en las primeras décadas del siglo XX, y cuya influencia en la escena española se dejó sentir con más fuerza en etapas posteriores como los años del régimen franquista.

La decadencia que empezó a sufrir la estimación de su obra se acrecentaría tras su muerte en 1916, con el surgimiento de las nuevas olas teatrales europeas y la entrada en escena de jóvenes dramaturgos, aunque no faltaran comentaristas que valoraran su aportación al teatro español. El diario $A B C$ habló, a este respecto, del «injustificado desdén que por él muestran las figuras cumbres de nuestro teatro» (01). Paradójicamente, su obra se siguió representando en los años que siguieron, sobre todo aquellas que le habían granjeado mayores elogios (De mala raza, El gran galeoto, Mancha que limpia, O locura o santidad...). El paulatino arrinconamiento de la obra de Echegaray entre las preferencias del espectador correría paralelo a la escasa atención que había recibido desde su invención por parte de un nuevo arte que, en muchos aspectos, era deudor del teatro: el cine.

\section{JOSÉ ECHEGARAY Y EL CINE}

Echegaray había definido el cine como «maravilloso juguete que perpetúa el movimiento» (García Escudero, 1962: 119), pero bien fuera porque la teatralidad de su obra fuera más intensa que la de otros dramaturgos, más apegada al medio para la que fue concebida, o porque nunca había concitado el interés de cineastas, la mayor parte de ella quedó en su original reducto de las tablas. De su vasta producción teatral, 67 obras estrenadas, solo El gran galeoto ha merecido la atención del cine universal con seis adaptaciones, mientras que otras tres obras de Echegaray también recibieron su correlato fílmico (De mala raza, A fuerza de arrastrarse y Mancha que limpia) en la etapa del cine mudo español. De este conjunto de adaptaciones, únicamente se puede visualizar El gran galeoto de Rafael Gil; el resto son películas desaparecidas de las que solo podemos hacernos una idea aproximada atendiendo a las crónicas periodísticas y archivos que dan fe de su existencia y de su mayor o menor aceptación, calidad y de las vicisitudes que en torno a ellas tuvieron lugar. 


\subsection{El cine mudo español y Echegaray}

En el cine mudo, la teatralidad se erigía en norma común de muchos de los filmes de este período, peculiaridad que quedaba magnificada en las adaptaciones de Echegaray, que, al perder el forraje verbal que envolvía sus obras, las interpretaciones debían ser más gestuales para diseñar con acierto las pasiones y fuertes emociones que desprendían las creaciones del dramaturgo madrileño. Durante ese tiempo, el cine español solo se fijó en tres de ellas: una, coetánea al dramaturgo, Mala raza; las dos siguientes, Mancha que limpia y A fuerza de arrastrarse, posteriores a su fallecimiento y con la consideración de su obra en franco declive crítico, que no de público.

\subsubsection{Mala raza (1912, Fructuós Gelabert)}

Mala raza fue la primera adaptación al cine que se realizó de una obra de José Echegaray, De mala raza (1904). Sin embargo, la puesta en imágenes de ésta sin los pertinentes derechos, unido al notable éxito que alcanzó la película, llevó a la Sociedad de Autores, en representación del dramaturgo, a demandar por plagio a Gelabert, quien, gracias a la inteligente labor de su abogado, ganó el pleito - Echegaray obtuvo una pírrica victoria al ver cómo el título original se modificaba por el de Mala raza - (Pozo, 1984: 23; Porter, 1985: 49). Sin poder acceder al visionado del filme, parece ser que las concomitancias entre obra teatral y adaptación cinematográfica eran más que evidentes. En el referente literario, Echegaray disocia valores suprahumanos como la dignidad y la honra de los ciudadanos de clase alta por el simple hecho de pertenecer a ella por nacimiento. Por boca del personaje Prudencio se insiste en la transmisión de las leyes de la herencia de padres a hijos, de tal forma que todo lo malo o bueno que hizo el ascendente redundará de manera irrevocable en su descendencia, la "fatalidad orgánica" para caracterizar a Adelina, de tal suerte que, en el momento crítico, ninguna prueba en contrario valdrá para anular su fatalidad y las sospechas que recaen sobre ella de adulterio son sinónimo de amarga realidad.

\subsubsection{Dos adaptaciones de José Buchs: Mancha que limpia y A fuerza de arrastrarse.}

No sería hasta doce años después, y transcurridos ocho desde el fallecimiento de José Echegaray, que el cine español adaptaría de nuevo su obra. En 1924, Film Española, una productora de nueva creación que se especializaría en zarzuelas y melodramas, encargó dos nuevos proyectos a su director estrella, el cántabro José Buchs - que el año anterior había filmado los primeros títulos de la productora: Rosario la Cortijera, Curro Vargas y El pobre Valbuena - para que adaptara al cine dos de las obras del dramaturgo madrileño de mayor éxito: Mancha que limpia y A fuerza de arrastrarse. Con estos filmes, Film Española pretendía continuar la tradición iniciada por Film-Art francés de transponer una obra de prestigio al lenguaje fílmico, aun manteniendo muchos de los mimbres que caracterizan al teatro, como la puesta en escena, los decorados o célebres intérpretes de la escena, con el ánimo de ampliar el espectro de población que podía acceder al conocimiento de la obra y que no podían permitirse el lujo de asistir al teatro, al tiempo que, simultáneamente, prestigiaban el medio cinematográfico que necesitaba del vehículo que le proporcionaba el teatro para dar renombre a sus propios productos.

Aun denostado por parte de la crítica teatral, lo cierto es que José Echegaray seguía siendo un valor seguro para las compañías teatrales. Prueba de ello era que no resultaba extraño ver en la cartelera un título de la amplia producción del dramaturgo. Aunque nunca terminó de salir del programa de los escenarios españoles en Barcelona se estaba representando en el Gran Salón Excelsior en 1914 -, el 3 de abril de 1923 el Teatro Fuencarral acogió la reposición de Mancha que limpia (1895), con Concha Torres interpretando el papel de Matilde y acompañada de Luis Echaide. La ascendencia de la que seguía disfrutando un fenecido Echegaray entre el público sería determinante para que Film Española decidiera trasladar a imágenes cinematográficas dos de sus producciones teatrales, que contarían para ello con la presencia de renombrados actores de la escena y un equipo técnico común a ambas producciones, encabezado por José María Maristany en la fotografía, Emilio Pozuelo en los decorados y Francisco Cejuela como ayudante de dirección.

Interpretada por Aurora Redondo, Carmen Viance, Modesto Rivas, Ana María Ferri, María Comendador, Mariano Asquerino y José Crespo - quien daría su salto a Hollywood a finales de la década con Revenge (Edwin Carewe, 1928), junto a Dolores del Río - y distribuida por Compañía Cinematográfica Hispano- 
Portuguesa, Mancha que limpia se estrenó en el Real Cinema de Madrid el 20 de octubre de 1924. Es un drama de amores pasionales donde el arrebato amoroso llega a su paroxismo con la muerte, con la mancha que limpia el honor ultrajado. Cómo el infundio, la envidia, la animosidad pueden hacer desgraciada a una persona; y cómo por el hecho de proceder de una familia desgraciada, carece de honra, de credibilidad, en suma, de autenticidad. La película conocería una posterior novelización de 32 páginas por Horta (Barcelona) el 4 de mayo de 1927.

A fuerza de arrastrarse, estrenada en el Teatro Español en 1905, hace referencia a la fábula El águila y el caracol, de Juan Eugenio Hartzenbusch, que contiene cierta crítica social:

¿Cómo con ese andar tan perezoso tan arriba subsiste a visitarme? (dice el águila al caracol). "Subí, señora contestó el baboso -, ja fuerza de arrastrarme! (Echegaray, 1959: 1243)

La obra cuenta la historia de cómo Plácido va subiendo en la escala social hasta ser miembro de la alta sociedad madrileña, a la que arriba desde su Retamosa natal, mediante añagazas, componendas y tejemanejes, y donde su talento no le lleva, lo hace la pillería. Pero su ambición lleva aparejada al mismo tiempo un efecto contraproducente: deja atrás su felicidad y bienestar a costa de auparse en el escalafón social, aun siendo consciente de que se convertirá en un miserable: un pequeño peaje que ha de pagar si quiere tener éxito.

José Buchs dirigió a Amalia de Isaura, José Montenegro, Pura de Benito, José Romeu, Antonio Martianes, Rafael Nieto, Modesto Rivas, Arturo de la Riva y María Comendador en su versión cinematográfica. El 29 de diciembre de 1924 fue estrenada en el Real Cinema de Madrid, aunque también se proyectaría en el madrileño cine Cervantes en febrero de 1925. En las páginas de $A B C$ se insertó un comentario que, más que una crítica, era una loa sin ambages, casi como si fuera una obra maestra: «Es una película muy cuidada, brillante de fotografía, interesantísima de asunto, acertada de dirección y con una interpretación acabadísima» (02).

Luis Gómez Mesa inquirió sobre los motivos que llevaron a Buchs a llevar estas dos obras de manera simultánea al cine, cuando no El gran galeoto, que se seguía representando en la escena con inusitado éxito. De cualquier forma, sostenía que «desprovistas sus creaciones escénicas de los diálogos se quedan en unas tramas melodramáticas, cuando no folletinescas» (1977: 97).

\section{INFLUJOS Y ATRACCIONES EN EL CINE DE LA OBRA MAGNA DE JOSÉ ECHEGARAY: EL GRAN GALEOTO}

Desde el estreno triunfal el 19 de marzo de 1881 de El gran galeoto, drama teatral en tres actos en verso y un prólogo en prosa, su recorrido por las tablas de toda España y de medio mundo parecía no tener fin. EI tratamiento de un tema universal, fácilmente extrapolable a cualquier cultura, como es la maledicencia y la envidia, por ser un drama de pasiones exacerbadas y amores vehementes, pero contenidos, moralista y efectista, puede explicar su amplio trayecto temporal y geográfico que conoció décadas de reposiciones y países de representación como no hubiera imaginado su autor. Su actualidad a lo largo de los años tuvo su correspondencia en el ámbito fílmico, al conocer diversas adaptaciones que, con mayor o menor fortuna, presentaron su obra a nuevas generaciones.

\subsection{El gran galeoto en el cine universal.}

Dos producciones, una de Estados Unidos y otra de Alemania, abren este capítulo, aunque la pérdida de los filmes y los escasos datos que sobre ellos existen, no permiten una valoración real de los mismos. La primera versión de El gran galeoto, The celebrated scandal, corrió a cargo de la Fox Film Corporation, quien encargó a Elaine Sterne Carrington que adaptara la obra de Echegaray en una producción que sería dirigida por James Durkin. Aunque no faltan webs que sostienen la codirección con J. Gordon Edwards (03), Alain Goble (1999: 708) y Aubrey Solomon (2011: 228) recogen en sus correspondientes estudios la dirección única de Durkin. De esta versión, pocos datos pueden ser contrastados: solo que su estreno en Estados Unidos tuvo lugar el 11 de febrero de 1915 y que fue protagonizada por Betty Nansen (Teodora), Edward José (Don Julián, que en esta 
versión es un diplomático español) y Wilmuth Merkyl (Ernesto).

Por su parte, Der Grosse Kuppler es una producción alemana de 1919 dirigida por Hubert Moest. En Alemania ya era conocida la obra de Echegaray, pues el 16 de abril de 1902 tuvo su estreno teatral en Dresde con cierta fortuna. Pero antes ya se representó como parte del programa del Teatro Alemán en Londres el 28 de enero de 1902, en la tercera temporada en el ya clausurado St. George's Hall de Londres, con 4 representaciones (Ulrich, 2016: 278).

El cine mudo de Hollywood produjo otras dos películas que tenían como referencia literaria El gran galeoto, pero pasado por la óptica de Charles Frederic Nordlinger, quien en 1908 había firmado una adaptación al inglés basada en la obra de Echegaray con ánimo de ser representada en los teatros anglosajones y que tituló The World and his wife. Ésta conoció una primera versión con el mismo título dirigida por Robert G. Vignola, que contaba con la producción de Cosmopolitan Productions y la distribución mundial de Paramount Pictures, con Montagu Love y Alma Rubens en sus roles principales. Vignola fue uno de los directores más prolíficos del cine mudo en Hollywood, dirigiendo, entre cortos y largos, casi cien títulos.

Estrenada el 12 de julio de 1920 (04), la pérdida del filme impide hacernos una idea de su calidad, aunque las crónicas de algunos medios nos ofrezcan algunas pistas al respecto. Así, el New York Times valoraba ciertos aspectos de la producción, como la base argumental y la interpretación de Alma Rubens, bien soportada en su trabajo por el resto de intérpretes. Pero, en sentido contrario, achacaba a la película cierta debilidad en el tratamiento de algunas escenas, tediosa en ciertas partes y el conjunto adolecía de falta de fuerza (05). El 29 de enero de 1925 se presentaría la versión de Vignola en el cinema X (Noviciado) de Madrid.

En 1927 Douglas Furber y Sylvia Thalberg firman un guion que vuelve a tener como base The World and his wife para una producción Metro Goldwyn Mayer dirigida por John M. Stahl, que tendrían como estrellas protagonistas a la pareja Ramón Novarro y Alice Terry, una de las parejas artísticas de mayor prestigio en la etapa silente de Hollywood, en la que sería su sexta y última película juntos (aunque en Los cuatro jinetes del Apocalipsis (Rex Ingram, 1921), Novarro tenía un pequeño rol). Según la web de la Biblioteca del Congreso, Lovers se estrenaría el 5 de febrero de 1927 (06).

Estamos ante otro filme perdido (que integra el catálogo de películas perdidas de MGM (07)) cuyo título nos incita a pensar en un desarrollo argumental con un contenido más pasional entre los personajes de Ernesto y Teodora (08). Mordaunt Hall, en las páginas de New York Times, la calificó de película absorbente y con fluidez en su narración (09). El crítico tiene una buena apreciación de Ramón Novarro, del que dice que está espléndido en la película, y Alice Terry, que aunque nunca ha sido especialmente expresiva, es la Teodora ideal, encantadora, tranquila y gentil.

Su proyección en España no estuvo exenta de dificultades. Al poco tiempo de su estreno en Estados Unidos ya era promocionada en España, como un hito más en la carrera del tándem Novarro-Terry. En La Vanguardia se hicieron eco del éxito de esta nueva producción MGM: «Ramón Novarro es el principal intérprete de la delicada producción titulada "Lovers" (Amantes), cuya acción se desarrolla en España, aunque sin corridas de toros, guitarras ni otros accesorios que parecían indispensables hasta la fecha para representar un asunto de ambiente español. En este film, en el cual trabaja también la insigne Alice Terry, intérprete de Mare Nostrum, queda claramente demostrado el nefasto influjo de las malas lenguas. Es un drama emocionante, donde puede verse el destrozo causado en la vida de tres seres completamente felices por la malignidad de un hombre sin escrúpulos» (10).

En octubre de ese mismo año el Gobierno español declaró la prohibición de exhibir Lovers (junto a Valencia, de Dimitri Buchowetzki) en todo el territorio nacional, quedando suspendidas las actividades comerciales de la Metro. Ello obligó a intervenir al embajador de Estados Unidos en España, Ogden H. Hammond, que se entrevistó a tal fin con el dictador Miguel Primo de Rivera. El hecho es que la película se había proyectado en Bruselas y Budapest y cayeron en la cuenta de que consideraban «despectivas contra la reputación nacional de España» (De Haro de San Mateo, 2003: 152). Parece, de esta forma, que se cortaron esas partes que pudieran resultar ofensivas hacia España para poder proyectarse la película, una prohibición que había durado poco más de un mes. 
Así y todo, hasta el 3 de enero de 1929 no se estrenó en España, con su primera proyección en el Capital Cinema de Barcelona, que la publicitaba como «una trama de incomparable emoción y belleza que refleja las pasiones desatadas y los odios y murmuraciones humanos». Las últimas proyecciones de la película se publicitaban en el cine Capitol en septiembre de 1929. En 1931 conocía nueva reposición en Barcelona y en junio aún se podía ver en el cine Comedia. En Madrid, en cambio, hubo de esperar al 10 de mayo de 1929 para asistir a su estreno en los cines Royalty y Cinema Palacio de la Música. El 3 y 4 de diciembre de 1929 también fue proyectada en el cine de la Flor de Madrid.

\section{EL GRAN GALEOTO SEGÚN RAFAEL GIL}

\subsection{Oportunidad de una nueva adaptación.}

A cuarenta años de su estreno, el prestigioso actor teatral Ricardo Calvo representaba la obra con éxito por el territorio americano. José Crespo, quien ya había intervenido en otra adaptación fílmica de una obra de Echegaray, Mancha que limpia, interpretaba al atribulado Ernesto de El gran galeoto en el teatro Windsor Square de Los Angeles el 14 de abril de 1928 junto a Elsa Chamberlain en la compañía teatral de Cecil E. Reynolds, tras haber dado el salto a Hollywood el año anterior. En los años 30 la compañía de Enrique Borrás y Margarita Xirgu estuvieron interpretando la obra en el Teatro Calderón de Madrid; la compañía de Rafael Rivelles hizo lo propio durante los cuarenta en teatros de media España, como Barcelona, donde ya había representado la obra con notable éxito en 1926, 1927 hasta noviembre de 1928 con su compañía en el Teatro Barcelona (junto a Ladrón de Guevara) y con Enrique Borrás haciendo de Don Julián y Rafael Rivelles de Ernesto.

Durante la posguerra, la obra seguía disfrutando de frecuentes reposiciones que mantenían viva la llama de su actualidad entre el público español de la época, y muy especialmente el madrileño. Desde 1941 y su reestreno el 3 de diciembre en el Teatro Español a cargo de Vicente Soler, fueron muchas las reposiciones del drama. Durante 1942, la compañía de Rafael Rivelles la estuvo representando en el Teatro Fontalba de Madrid, acompañado de otro grande de la escena, Enrique Borrás, donde seguía representándose con éxito en 1945; el Teatro Infanta Isabel era el espacio destinado a la interpretación de la obra en 1945 con Borrás y el galán Rafael Calvo; en octubre de 1950 se seguía interpretando en el Teatro Calderón de Madrid con la compañía de Alejandro Ulloa y con Ricardo Calvo, que ya había sido parte de la misma obra en el homenaje que se le rindió a Echegaray con motivo de su Premio Nobel de Literatura en 1904, como cabeza de cartel. Según García Ruiz y Torres Nebrera, «no obstante la irreparable vejez de un verso ripioso, grandilocuente y sin aliento, parece que todavía el público apreciaba su sentido de la pasión teatral, desmedida pero no falsa» (2003: 33).

No resulta extraño, de esta forma, el interés suscitado en Rafael Gil para filmar una nueva adaptación de la obra al cine. Un motivo más poético alude Gil en la puesta en marcha de su versión como fue su reacción a la versión filmada por Stahl al estimarla como «muy estilizada, muy aséptica» (Gregori, 2009: 84). Hace caso omiso a una versión más reciente que había producido el cine mexicano y que es de suponer que el director madrileño no había visto, al no haber tenido estreno español, Festín de buitres (Ramón Peón, 1949). Producida por Pereda Films (Ramón Pereda), fue filmada a partir de enero de 1946 en los estudios Azteca. Estrenada el 13 de enero de 1949 en los cines Acapulco, Apolo, Gran Vía y Majestic (Agromonte, 2003: 275). Poco se conoce de esta película, excepto que algunos de los nombres de los personajes fueron modificados y que el título Festín de buitres hace referencia al cuadro que Ernesto pinta como representativo de la maldad de los hombres (García Riera, 1969: 100).

En ese tiempo, el actor Rafael Durán había puesto en marcha, junto a Joaquín Romero Marchent, la empresa productora Intercontinental Films. En 1951 habían producido una película cuyo prestigio se ha ido incrementado a lo largo de los años, Cielo negro, de Manuel Mur Oti, influenciada por los cantos de sirena del neorrealismo italiano. Por eso puede sorprender el giro experimentado con la producción de El gran galeoto, pero no se puede obviar que éste era el tipo de producciones mayoritarias de esos años, de capa y espada de cierto regusto añejo, pero de impecable factura técnica y artística. 
siglo XIX, como sus adaptaciones de las obras de Alarcón, El clavo y La pródiga, ambas con su amigo Durán, con lo que no debe extrañar la opción de Gil para encabezar este proyecto, que ha de servir de corolario de su primera etapa, antes de su colaboración con el guionista y productor Vicente Escrivá durante los siguientes siete años.

En la obra de Echegaray el director vislumbró posibilidades fílmicas, aunque, si bien fue capaz de desprenderse de la teatralidad en la puesta en escena, sobre todo en los exteriores, no lo haría tanto en los diálogos, de los que se hicieron cargo el propio sobrino nieto del ínclito literato, Alfredo - que ya tenía cierta trayectoria como guionista en el cine español con títulos como Deliciosamente tontos (1943) y Ella, él y sus millones (1944), ambas de Juan de Orduña, o Un hombre de negocios (Luis Lucia, 1945) -, y el periodista y Magistrado de la Audiencia Territorial de Madrid José Antonio Pérez Torreblanca. Sin embargo, la coincidencia de su rodaje con producciones coetáneas como Día tras día, de Antonio del Amo, Surcos, de José Antonio Nieves Conde, la mencionada Cielo negro o la ópera prima de Luis García Berlanga y Juan Antonio Bardem, Esa pareja feliz que se estrenaría, por problemas de censura, en 1953 -, todas ellas de marcado carácter social y herederas de la tendencia neorrealista que llevaba varios años hegemónicos en la cinematografía italiana, lastraron adaptaciones teatrales como la de Gil. Incluso el teatro que a la sazón se representaba en nuestros escenarios difería en contenido y forma con el representado en la antesala del siglo XX y que se concretaría en la magna obra de Antonio Buero Vallejo, Historia de una escalera (1949). Todos estos obstáculos lastraron en origen la película de Rafael Gil, pero ello no es óbice para observar y remarcar sus muchos aciertos: así, unas buenas interpretaciones, sobre todo de José María Lado - cuya voz fue doblada para la película por José María Oviés -, como Don Julio, y de un joven Fernando Sancho, como Nebreda, unidas a las correctas del dúo protagonista, Rafael Durán y Ana Mariscal, y a un siempre excelso Juan Espantaleón, en el papel del hermano de Don Julio, Severo. Pero era en el apartado técnico donde estaba el máximo aliciente de esta producción: la fotografía, dirigida por dos grandes maestros, Michel Kelber para los interiores y Enrique (Heinrich) Guerner, para los exteriores; unos decorados ricos y suntuosos, en línea con la posición social de sus protagonistas, excelentemente diseñados por Alarcón; una música de Manuel Parada, que alterna momentos dramáticos con subrayados burlescos, como los de la secuencia de la caza de la perdiz; y magníficos momentos del montaje de José Antonio Rojo, como la secuencia en que, tras extenderse la maledicencia - símbolo de El gran galeoto, título de un poema sinfónico que le inspiró a Ernesto el título de los amores de Polo y Francesca de La Divina Comedia, de Dante - por la relación "inmoral" entre Teresa y Ernesto, se crea un chotis que, de inmediato, es cantado por todo el pueblo, alternándose distintos planos en los que se observan las diversas formas de manifestación de la música.

Si José Echegaray había jugado en su obra con la ambigüedad del amor que subyace entre Ernesto y Teodora (en el filme Teresa la Bisbal), esposa de Don Julio, su protector y viejo amigo de su padre, el guion de Gil, Echegaray y Torreblanca pretende ser más diáfano en la presentación del amor, callado pero evidente, que Ernesto siente hacia Teresa desde los tiempos en que ésta era actriz de teatro y que devendrá imposible cuando, después de que el azar los reúna de nuevo, descubra que es la mujer de Don Julio.

El 7 de febrero de 1951 fue autorizado el guion de esta producción de 5.996.426,97 pesetas (algo superior a lo que inicialmente se había presupuestado, 5.300.000), aunque el rodaje ya estaba en marcha desde el 27 de diciembre de 1950, con interiores filmados en los Estudios Ballesteros y exteriores en Villa del Campo y Bilbao, dándose por finalizado el 22 de abril de 1951.

Clasificada en primera categoría por la Junta Superior de Orientación Cinematográfica el 23 de julio de 1951, fue autorizada únicamente para mayores de catorce años. Aun obteniendo una calificación tan alta, resulta paradójica la reacción inmisericorde mostrada por los censores, cuyos informes no tienen desperdicio (11). Guillermo de Reyna la califica de «melodrama trasnochado y artificioso, que pese a cierta riqueza de medios materiales, acusa los defectos graves de un tema, que a su falta de interés actual, suma una realización defectuosa, llena de escenas forzadas y exageradísimas, que privan de emoción a la película, que en ocasiones deriva hacia lo grotesco». Javier Elorza habla de «argumento fuera de la época actual». Soriano, por su parte, es más duro al señalar desacertada la realización de Gil, concluyendo que «este trasnochado argumento, es mi opinión, que nunca debió ser empleado para una película». Para finalizar, Pedro Mourlane, quizás consciente de las tímidas propuestas cinematográficas que se acercaban a la realidad del momento, recalcó que «en el 
paso al cine el elemento anacrónico malogra el esfuerzo de los autores».

Tras su estreno en el cine Callao de Madrid el 15 de octubre de 1951, las críticas fueron moderadamente favorables: Gómez Tello, en Primer Plano señaló, ante el temor manifiesto de que fuera una película excesivamente teatral, que Rafael Gil «ha evadido el peligro de los gritos con una severa disciplina de los actores» (12). El cronista, aunque alaba el traslado a la gran pantalla de la obra con una gran calidad artística y elementos como la fotografía, las interpretaciones de Durán y Mariscal y la secuencia del duelo, acaba achacando a Echegaray los fallos que puedan existir, como la artificiosidad de la escena del circo (13). En $A B C$, Gil Gómez Bajuelo escribió que «toda la fuerza dramática de la obra se ha canalizado con dinamismo de cine en esta película, para lo que se ha precisado hábilmente eludir la rigurosidad argumental en beneficio de la técnica cinemista (sic). Ha constituido, por consiguiente, un acierto de acusado relieve, en el que preside la originalidad. Se ha conseguido, por tanto, un filme de gran interés, sin la duda y sin esa lentitud que parecía adscrita a las adaptaciones teatrales» (14). En Ecclesia se argumentaba que «el tema es fuerte y escabroso, pero está tratado con corrección de formas. Es, por tanto, un espectáculo para personas mayores» (15).

\section{2. ¿Teatro filmado o filme teatral?}

Rafael Gil, en su propósito de traslación del drama de Echegaray a la pantalla cinematográfica, opta por una adaptación integral del referente literario. No obstante, a fin de diluir la rémora teatral, intenta, en palabras de Sánchez Noriega, «airear la obra» (2000: 73), con profusión de escenarios, la salida de las cámaras al exterior, la incorporación de la secuencia de la caza, sustitución de la declamación en verso por la prosa, concesión de una mayor relevancia a personajes secundarios como el Vizconde de Nebreda e incorporación de otros siquiera sugeridos en la obra teatral, como el padre de Ernesto... Asimismo, potencia, al contrario que la obra teatral, el ambiente de maledicencias y malsanas insinuaciones que se va extendiendo en todos los mentideros madrileños, desde el foro parlamentario hasta el callejero.

Empero, el guion resultante de esta labor de aireación no fue suficientemente valorado por los vocales de la Junta en su obligada presentación al aparato censor el 14 de octubre de 1950, como se infiere de algunos de los informes particulares. Así, José Luis García Velasco encontraba escaso su valor cinematográfico, aunque calificaba de correctos los diálogos. En su informe exponía la inoportunidad de llevar al cine El gran galeoto si lo que se pretendía era revitalizar la memoria del autor decimonónico ante la nueva generación teatral, de ahí que auguraba «una película vulgar con ribetes teatrales» (16):

Si El gran galeoto tiene sus indiscutibles valores no van éstos en función del tema en sí, que es lo único aprovechable en la adaptación cinematográfica. La obra original tiene otros valores que se pierden por completo en el guión y por todo ello francamente creemos que no merecía la pena tal empresa (17).

Tesis a la que se abonaba igualmente Fray Mauricio de Begoña al sostener en su informe que «sobre este guión ha de recaer el mismo juicio que sobre la obra teatral, la cual hoy es un relato de tiempos pasados, de puro romanticismo que nuestra época no siente, aunque sea siempre valedera la tesis de los daños que causa la maledicencia» (18). Fermín del Amo, por su parte, no era aún consciente del nuevo rumbo que se pretendía realizar en el cine español, limitando las producciones de época, al señalar que «salvo el comentario de que nuestro cine puede tener especial predilección por los dramas de tipo social y ubicados en el pasado siglo XIX, encontramos aceptable el presente guión que si no viene a traer inquietudes nuevas al celuloide hispano, en cambio está desarrollado con acierto, si bien con notoria brevedad ya que aparte de su escasa longitud, dedica una buena parte a la creación de un ambiente de murmuración que la ocupa un cierto número de planos que podrán reducirse para hacer más ágil el guión» (19).

En su labor de adaptación, Gil opta por un discurso lineal en el tratamiento cinematográfico de El gran galeoto, relegando la opción del flashback, para contar las vicisitudes que han llevado a Ernesto, Teresa y don Julio a vivir bajo el mismo techo y ser objeto de maledicencias e infundios, punto de arranque de la novela de Echegaray. Y lo hace precisamente en un escenario teatral, como en Teatro Apolo, al que Ernesto Acedo (Rafael Durán) acude todas las noches para disfrutar de la actuación de Teresa la Bisbal (Ana Mariscal). La actriz, desde la platea, es consciente de que solo tiene ojos para ella y que cuando no se halla en escena, se dedica a leer el periódico. En un tiempo en el que ser actor o actriz no estaba bien visto (despectivamente, 
llamados cómicos o, como el padre de Ernesto los tachaba, titiriteros), paradójicamente muchos espectadores hallarán en el escenario una vía de escape a sus anodinas vidas. En este marco tiene lugar una escena que es clave para el desarrollo posterior del filme y que deja claro el posicionamiento de Gil ante la relación amorosa entre Ernesto y Teresa, a la que priva de la ambigüedad con que la había envuelto el dramaturgo. Don Julio Villamil (José María Lado), hombre de Estado, banquero y honrado a carta cabal, también asiste a las representaciones de Teresa y, aunque le dobla la edad, siente un intenso amor hacia la actriz. Ernesto es más pragmático y su amor, sincero: un amor que se superpondrá al de Don Julio, anulándolo, alzándose triunfante sobre él, en la escena en que, mientras el banquero - que ha acudido al camerino de Teresa después de la función - le habla, ésta lee una carta enviada por Ernesto, en la que no solo declara su amor, sino que también le anuncia que no volverá a verla. La voz en off de Ernesto va mezclándose con la de Don Julio, hasta que, paulatinamente, ésta se apaga.

Ernesto es compositor e hijo de un importante empresario naviero de Bilbao, Ángel Acedo (Ramón Martori), que es a la par trabajador, comprensivo, un símbolo de honestidad y sacrificio... Su afán por ganar dinero no es solo para acumular riquezas, sino, en un acto de altruismo, para repartirlo entre sus trabajadores, negando, pues, la apropiación de la plusvalía que teorizaron Marx y Engels. En el último tercio del siglo XIX, comienza a destaparse una época de enfrentamientos sociales, más intensa desde que tiene lugar la toma de conciencia de clase del proletariado, con la emergencia de movimientos sociales de hondo calado como el comunismo y el anarquismo. Estamos, pues, ante una etapa conflictiva de nuestra historia que choca con la paz social que oficialmente vive la España de 1951. Qué mejor forma, pues, de destacar ésta que confrontándola a los inestables años del parlamentarismo tras la Gloriosa de 1868. En paralelo podemos realizar una lectura de la película contraria a los intrigantes, huelguistas y conspiradores de clases bajas, en contraposición a las buenas virtudes que el autor presupone como seña de identidad de las clases pudientes. Una lectura que también se podría actualizar denostando la lucha de clases, la huelga y ofreciendo la necesidad del trabajo en común en pos de los mismos objetivos. Resulta esclarecedora, de esta forma, la sentencia de don Ángel a su hijo, en el instante de su muerte tras haber sido víctima de un atentando a manos de un anarquista: «Busca la compañía de los hombres leales, de los de mi clase». Esclarecedora por vincular lealtad y posición, una posición que nunca habría de tener la titiritera Teresa la Bisbal.

En su lecho de muerte, su padre insta a Ernesto a que vuelva a Madrid a ver a Julio, amigo de él de hace muchos años y al que han nombrado albacea testamentario para que administre la enorme riqueza dejada por Ángel. Una conexión oculta, azarosa, existe entre Ernesto y Julio: éste se ha casado con Teresa, pese a la diferencia de edad, que ha abandonado su vida como artista, con lo que los dos están enamorados de la misma mujer. Pero Julio desconoce qué relación ha tenido Ernesto con Teresa. El reencuentro entre Ernesto y Teresa (o mejor, primer encuentro, pues nunca fueron formalmente presentados) nos sitúa a ésta casada con Don Julio. Quizá el abandono de su fiel espectador la ha llevado a tomar tal decisión, pues, desde ese momento, Gil se centra en la vida de Ernesto, dejando de lado a Teresa y su mundo. Cómo y por qué se ha llegado a casar con Don Julio, un hombre bueno y honrado, como Ángel de Acedo, es una información de la que carece el espectador. Sí asistimos a ese primer contacto entre Ernesto - que ha pasado a heredar la fortuna y posición en la empresa de su padre tomando, por consejo de éste en su lecho de muerte, a Don Julio como albacea - y Teresa, que, en un momento de nerviosismo, tras reconocerlo, tira sin querer un espejo al suelo cuyo cristal se hace añicos. El director nos muestra entonces un plano de ella reflejada en uno de los trozos del espejo, mientras que en otro de ellos aparece la imagen de Ernesto: en un acto metafórico, se muestra una relación rota, los dos separados por el matrimonio de ella, algo que él confirmará más tarde cuando eche al fuego los bocetos que de la actriz que guardaba (Figs.1 y 2). 


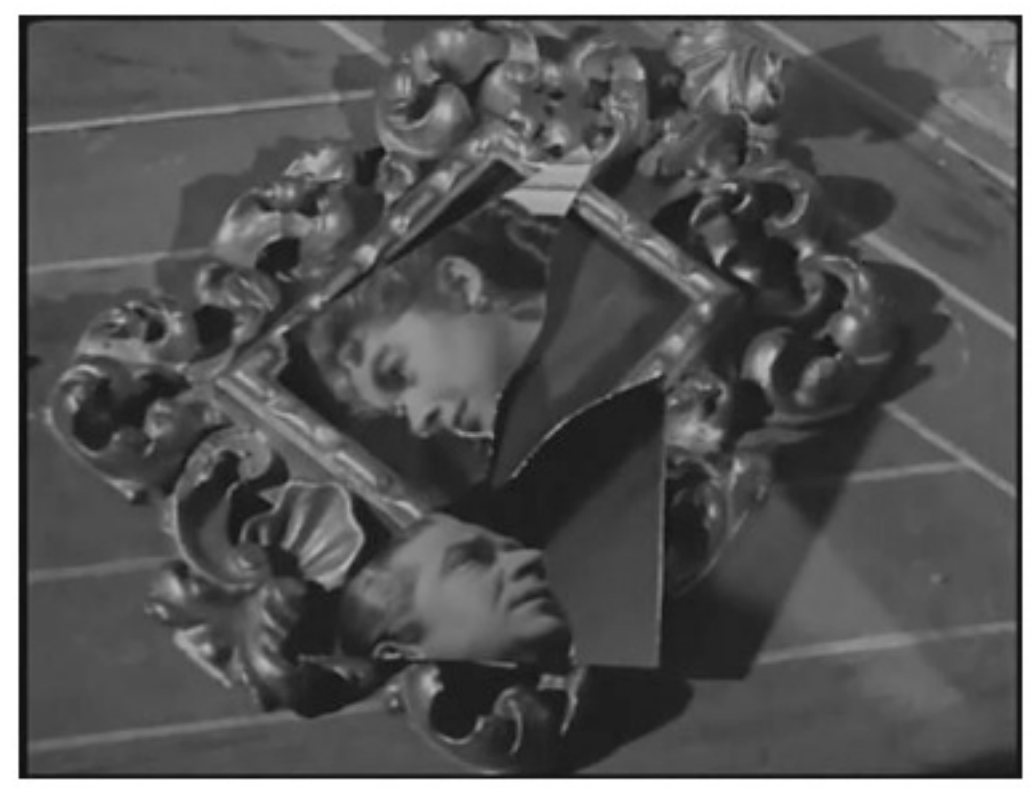

Fig. 1

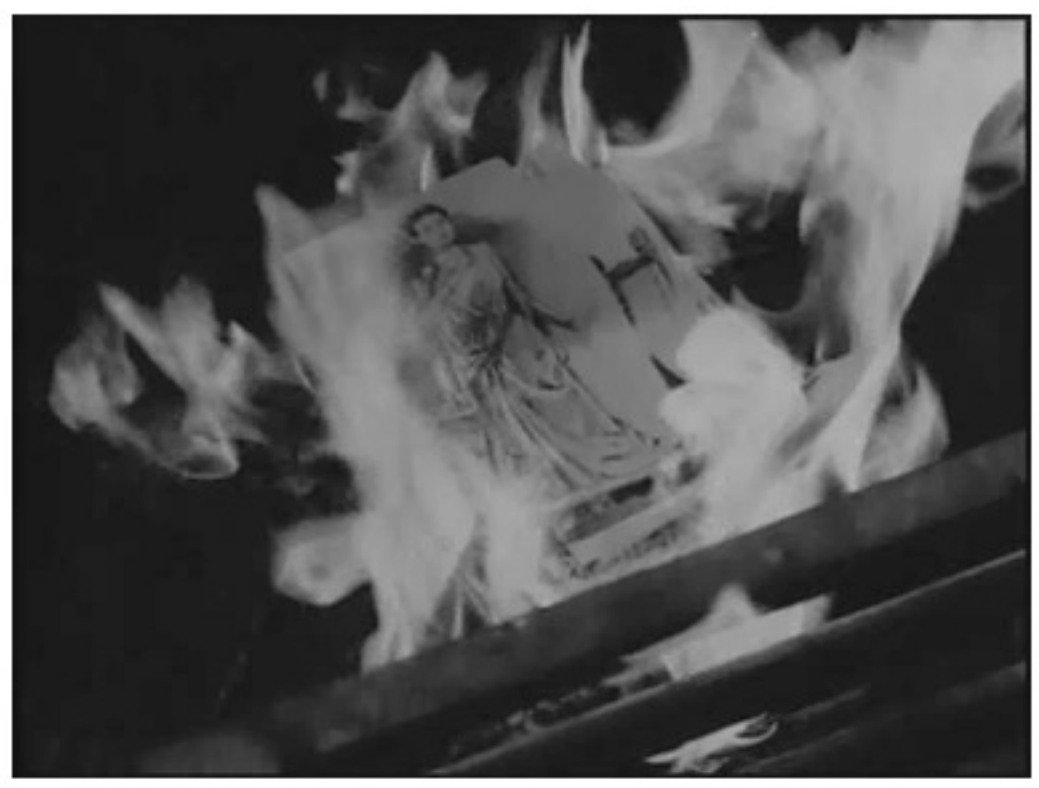

\section{Fig. 2}

Gil pretender difuminar la teatralidad con las escenas rodadas en exteriores, fotografiadas por Enrique Guerner, como la secuencia de la caza, donde por error, don Julio es herido por un disparo de una escopeta de caza y en esa situación, Teresa y Ernesto se hallan alejados del grupo e ignorantes de la situación, con lo que dan pábulo a todo tipo de fabulaciones que desembocarán en murmuraciones públicas y privadas. Ello da pie a que incluso el político Enciso (Félix Fernández) escriba una letra que se convertirá en un chotis, De campo ¿eh?, mordaz e hiriente, que empieza a ser conocido por todo Madrid, desde artistas a cocheros y panaderos. El propio Julio es ignorante de este hecho hasta que su hermano Severo (Juan Espantaleón) le comunica la situación.

En la secuencia del Parlamento alcanza la maledicencia su paroxismo. Con su inclusión, se vuelve a inferir una notoria reprobación del sistema democrático. Con más intensidad incluso que en La pródiga, donde Guillermo de Loja era objeto de los infundios de sus correligionarios, en El gran galeoto se ponen de manifiesto las manipulaciones, corruptelas e insidias por encima de la búsqueda del interés social y de una representación leal de sus votantes. Las discusiones en el foro están presididas por el vocerío sin orden ni concierto, las acusaciones y las interminables ausencias de acuerdos. A ello se añade que El gran galeoto, la maledicencia que arrastra y destruye a los hombres de bien, alcanza su punto álgido en las habladurías informales de los 
salones parlamentarios y en las burlas que los políticos realizan con ánimo de zaherir al noble don Julio. A estas irregularidades democráticas da más relieve Rafael Gil que el propio Echegaray en el referente literario, un Echegaray que, como miembro del Gabinete de Manuel Ruiz Zorrilla, vivió de primera mano los intensos debates en la Cámara.

Ernesto explica a Teresa en qué consiste el poema sinfónico que está escribiendo: El gran galeoto. Más que a la etimología del vocablo, la ocultación de un amor ilícito, galeoto hace referencia a la maledicencia pública que convierte en ilícito un cariño que no supera los límites de la simple atracción, de un amor platónico, y del que no se muestran indicios ciertos que demuestren lo contrario, más allá de las apariencias que se erigen triunfantes sobre las certezas.

El joven decide salir de la casa, como única salida a la situación. Pero observa que la maledicencia sigue su curso: escucha cómo el Vizconde de Nebreda (Fernando Sancho) y sus acólitos siguen burlándose de Teresa y, tras golpearle, es instado por Nebreda a batirse en duelo para reparar el honor dañado. Pero enterado don Julio, decide sustituir a Ernesto en la contienda, por su honor, pero es herido de muerte por el Vizconde. El duelo entre ambos está filmado mediante el uso de la grúa que da como resultado un plano secuencia dotado de gran simbolismo. La cámara de Kelber va realizando un suave movimiento descendente que lleva desde las sombras de ambos contendientes luchando en el piso superior (Fig. 3) hasta el piso inferior donde se encuentran Ernesto y Teresa - que ha acudido a él para implorarle que olvide su propósito de batirse con el Vizconde - a los que se acerca hasta encuadrarlos en plano americano (Figs. 4, 5, 6 y 7), en una interconexión de situaciones que subraya su responsabilidad, aun impremeditada, respecto a la intención de Don Julio de resarcir su honor.

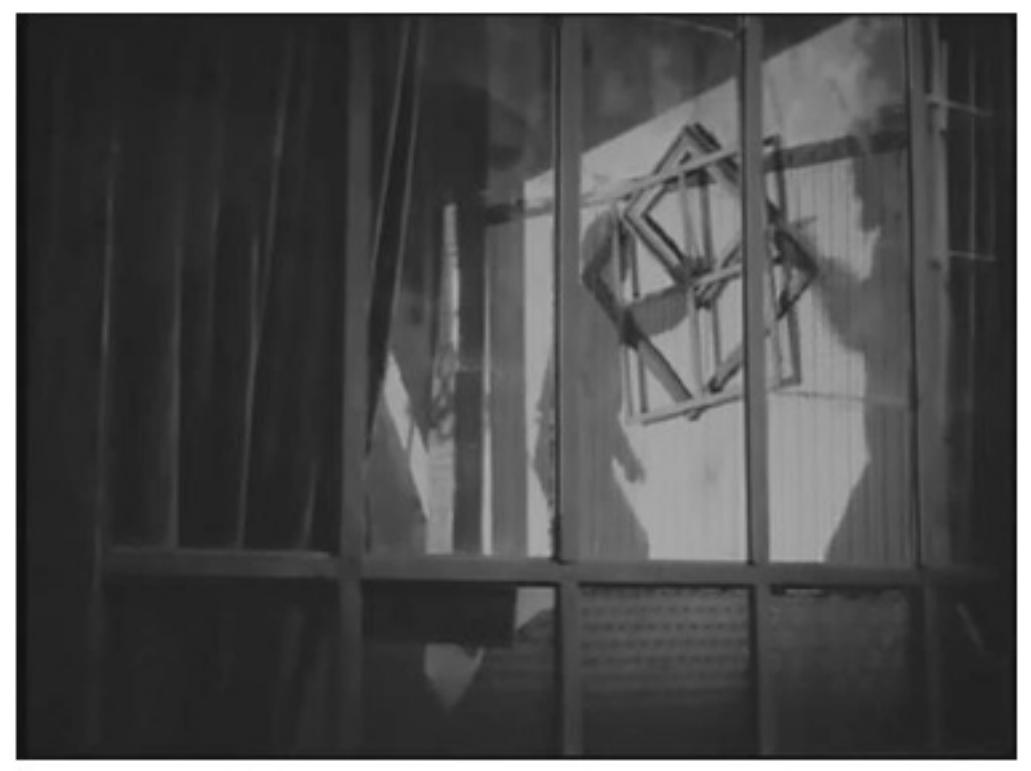

Fig. 3 


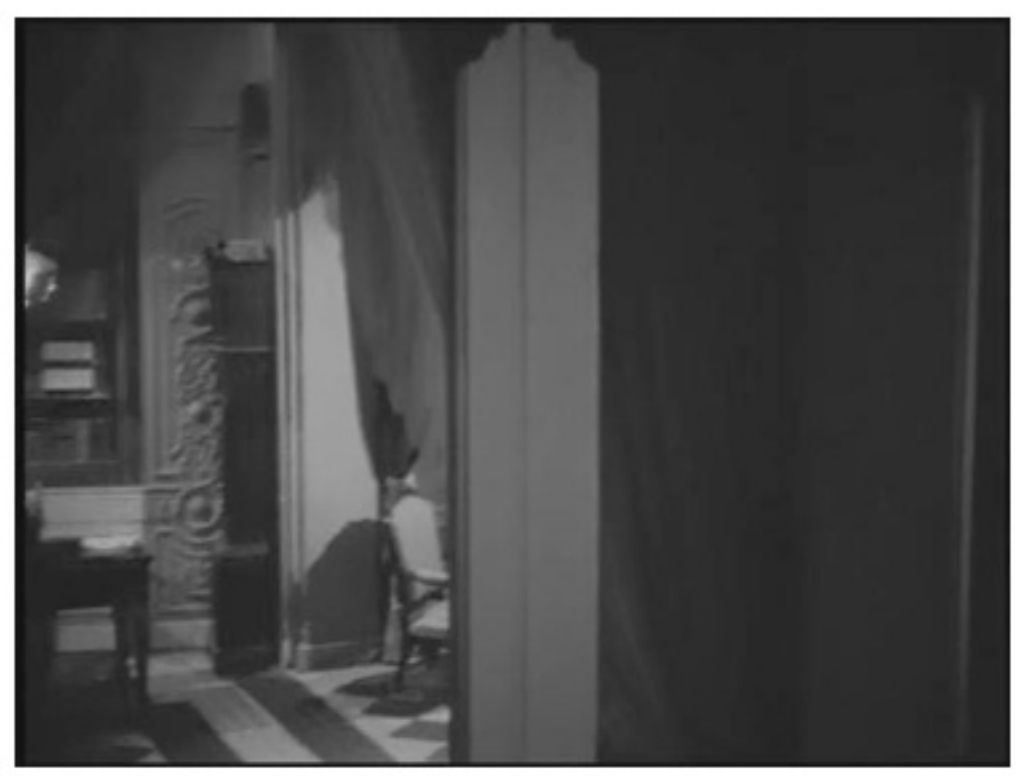

Fig. 4

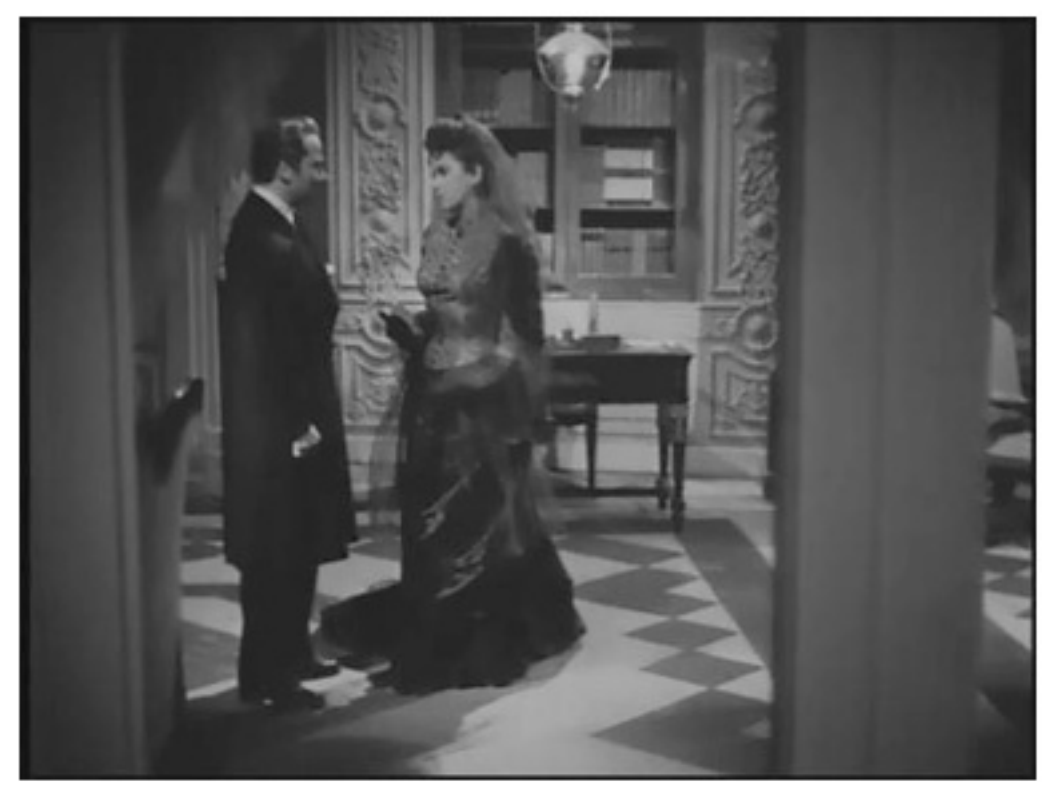

Fig. 5 


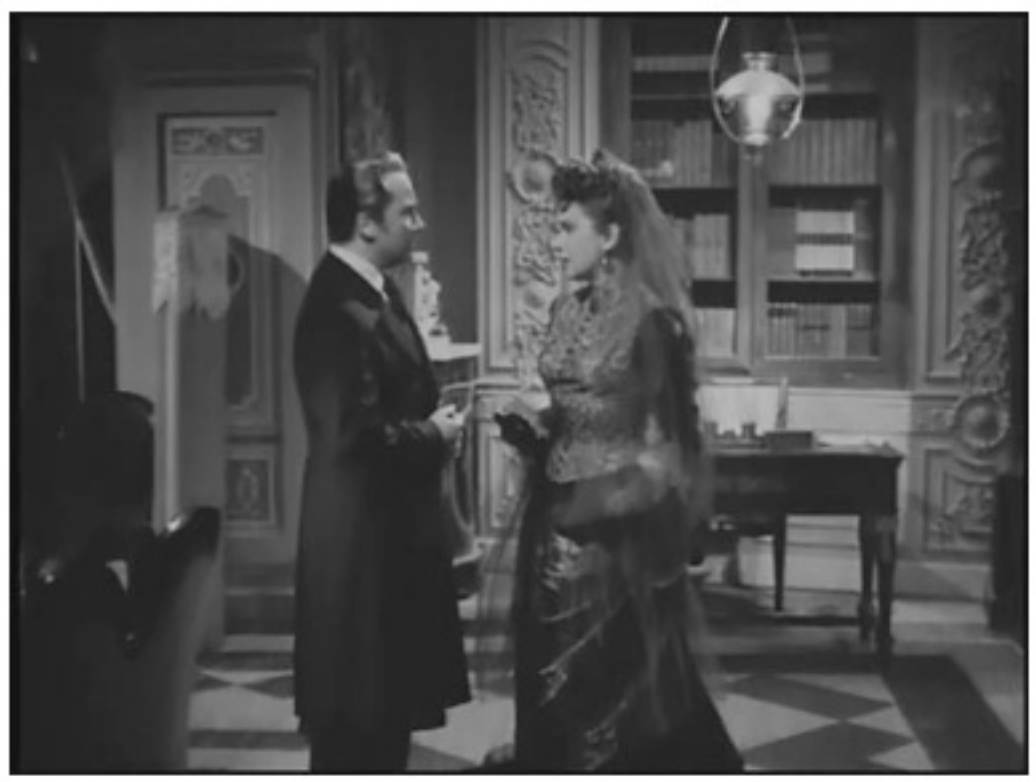

\section{Fig. 6}

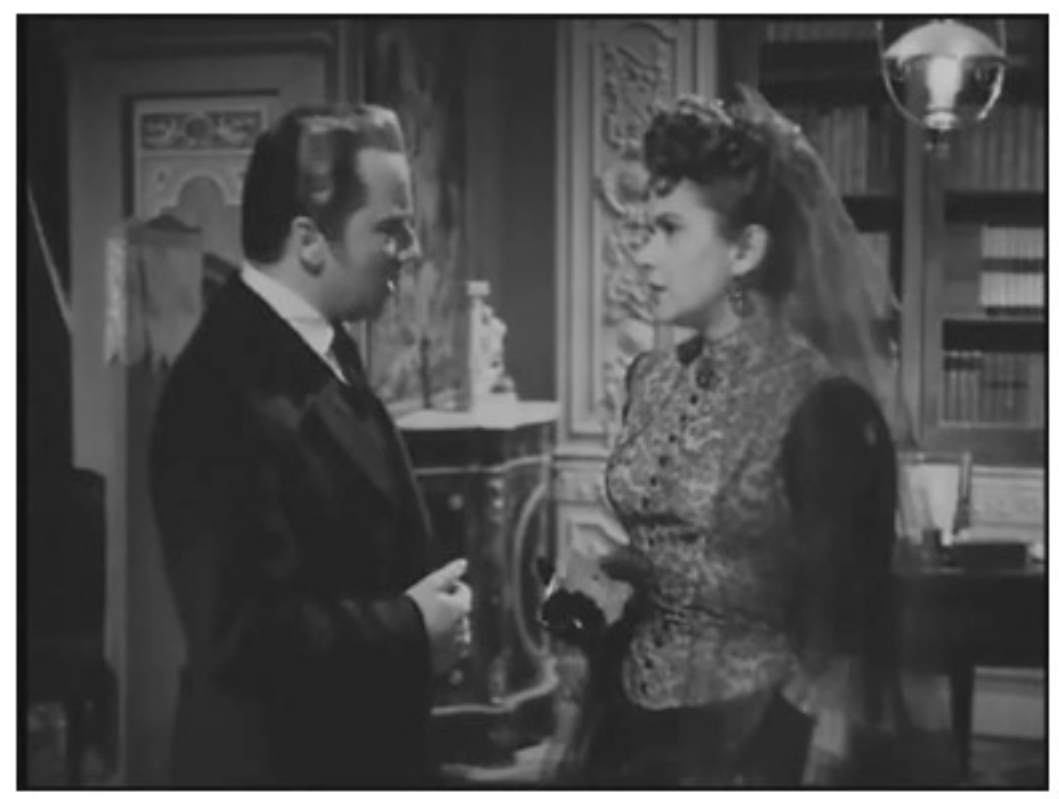

Fig. 7

La búsqueda de venganza de Ernesto que le lleva a enfrentarse al Vizconde tiene un mayor desarrollo en pantalla, con una combinación en montaje de una rápida sucesión de planos y otros en los que cobra protagonismo el movimiento de la grúa, desarrollada entre los pasillos y las escaleras de la casa, la mayor parte de ella sin música - algo que confiere un alto grado de tensión a la secuencia -, que solo hará su aparición en el momento en que el personaje interpretado por Fernando Sancho caiga al vacío a través de una ventana, muriendo en el acto. Esta secuencia había merecido especial atención a los censores en el análisis del guion. Bartolomé Mostaza señaló que a nivel moral no encontraba reparos reseñables puesto que «salvados todos los obstáculos, el duelo sale condenado por inmoral e inútil» (20). Fermín del Amo, por su parte, recalcó que «el duelo se condena por las palabras de Teresa. Únicamente queda sin castigo Ernesto, quizás debiera sugerirse que sufre la acción de la justicia» (21). Sobre esta secuencia, Fray Mauricio de Begoña adujo que «el duelo reprobado en principio, se escenifica como ambiente y hecho histórico de una época» (22). En el resultado del duelo Gil sigue fielmente lo escrito por Echegaray, rechazando la propuesta del censor José Luis García Velasco, que, sin más justificaciones, sugería que Ernesto no debía matar a Nebreda, sino simplemente herirle (23). El hecho de que la narración tenga su marco temporal en el siglo XIX, con todo lo que conlleva de época pasada y superada, y que se halle en las páginas del original literario dieron luz verde a la 
admisión del duelo en la película, una cuestión, por lo demás, que no dejaba de ser baladí, una vez admitida la conformidad moral del conjunto.

Don Julio ve que su mujer está en su casa y antes de exhalar su último suspiro, la repudia. En un final descorazonador, Severo le cierra la puerta de su casa a su cuñada. Todos la creen culpable. Ella es expulsada de su casa, aun siendo inocente, cuando la simple sombra del adulterio ha planeado sobre ella. Ernesto y Teresa acaban yéndose juntos, pero han sido rechazados por la sociedad. Para el final, una frase de Ernesto a Teresa en la que se pone a Dios como testigo privilegiado de a quién amó Teresa y cómo, a partir de ese momento, sus caminos se unirán como consecuencia de la maledicencia humana: «Pregúntale a Dios por la verdad de tu corazón y verás cómo mañana, cuando todos nos odien, tu corazón te dice que son ellos los que han unido nuestro destino para siempre».

El gran galeoto podría calificarse, ante todo, como una película de capa y espada, pero no en la acepción conocida del género de aventuras: aquí nuestros personajes tienen la capa del caballero burgués decimonónico y la espada de quien resuelve las afrentas al honor con un duelo a muerte. Una película que comienza a ser extemporánea, que cierra a destiempo la década de los cuarenta, trufada de títulos semejantes, y que en su año de estreno ha de competir con producciones de signo bien distinto, con un enfoque neorrealista - aunque algunos recubiertos con la correspondiente capa católica - que auguran tímidamente la presencia de un cine más cercano a la realidad, sin olvidar el que sigue siendo predominante, el cine de gola y levita en terminología de García Escudero (1954: 11). Atento a esta nueva vía, la productora de Rafael Durán había puesto en marcha, como mencionábamos más arriba, la película de Mur Oti Cielo negro. El propio Gil acometería a partir de ese momento otro tipo de proyectos que se alejaban de este tipo de cine que había frecuentado con algunas de sus producciones y al que no volvería hasta 1971 y Nada menos que todo un hombre, en plena efervescencia de adaptación de nuestros clásicos literarios. Ciertamente, aunque es un cine conservador y melodramático, no siente añoranza hacia esa etapa de nuestra historia, mal puede idealizar el pasado, como señalaba Pérez Bowie (2008: 84), cuando hay una velada crítica al parlamentarismo y las denodadas pugnas que en su seno acaecían, así como a la lucha de clases, elementos a los que dota de un marcado protagonismo en el curso de la narración, así como a la maledicencia e insidias, males comunes a cualquier época.

\section{CONCLUSIONES}

La única adaptación que ha llegado a nosotros es El gran galeoto de Gil, con lo que la mejor o peor fortuna que ha alcanzado la figura de Echegaray en el cine solo podemos estimarla en función de crónicas coetáneas y sesudos estudios. La fuerza de El gran galeoto desde su estreno en 1881 se dejó notar en el recién inventado cinematógrafo. La necesidad de conquistar los mercados extranjeros fue determinante para que los avispados productores de Hollywood pusieran su atención en la literatura europea. Echegaray no fue una excepción y El gran galeoto serviría para tres adaptaciones que recibieron en su tiempo gran publicidad, en especial la protagonizada por el dúo Alice Terry-Ramón Novarro. Presumiblemente, la química que despertaba la pareja cinematográfica y las pasiones que despertaban en el público pesaron más en la consideración del filme que el referente literario.

La obra de José Echegaray tuvo escasa fortuna adaptadora en nuestro cine. Durante la etapa silente, pocas de sus producciones conocieron su traslación a la gran pantalla, pero, como teatro filmado, eran interpretadas por actores de la escena, que debían contener su capacidad declamatoria e impulsar su labor gestual, en una aproximación a la pantomima. El verbo arrollador del dramaturgo veía frenada su fuerza por la incapacidad del cine de otorgar palabra a la imagen. Paradójicamente, la llegada del sonoro no conllevó una lluvia de adaptaciones y aunque su obra seguía representándose en las tablas, solo Rafael Gil se atrevería con una nueva versión de El gran galeoto en 1951.

Por encima de las voces críticas que calificaban de trasnochado y superado el teatro de Echegaray, otros comentaristas, como Lázaro Ros señalaba que «seguimos siendo un país de retóricos, y que nuestro teatro, encharcado hoy de verborrea y de doctrinarismo - cuando no de ingenio con vuelo de codorniz -, necesita una buena sacudida de estética energética: de acción, emoción, sublime horror dramático. Una versión nueva del 
teatro de Echegaray» (Echegaray, 1959: 43), concluyendo que «Echegaray es el hombre de la estética dinámica: de la acción» (Echegaray, 1959: 42). Sin embargo, el escaso eco que su obra había tenido hasta entonces en el cine, y particularmente en el nuestro, se acabaría diluyendo con el digno corolario a ésta que fue la película de Rafael Gil.

\section{REFERENCIAS BIBLIOGRÁFICAS}

AGRAMONTE, Arturo; CASTILLO, Luciano (2003): Ramón Peón, el hombre de los glóbulos negros. La Habana (Cuba): Editorial de Ciencias Sociales.

AMERICAN FILM INSTITUTE (1971): The American Film Institute Catalog of Motion Pictures produced in the United States, F2, Feature Films, 1921-1930. Los Angeles.

ÁVILAARELLANO, Julián; MENÉNDEZ ONRUBIA, Carmen (1987): El neorromanticismo español y su época. Epistolario de José Echegaray a María Guerrero. Madrid: Consejo Superior de Investigaciones Científicas.

BENTLEY, Bernard P.E. (2008): A companion to Spanish Cinema. Woodbridge: Tamesis.

DE HARO DE SAN MATEO, Ma Verónica (Coord.) (2003): La comunicación a través de la historia . Madrid: Visión Libros.

ECHEGARAY, José (1959): Teatro Escogido. Madrid: Aguilar.

GARCÍA ESCUDERO, José María (1954): La historia en cien palabras del cine español y otros escritos sobre cine. Salamanca: Publicaciones del Cine-club del SEU.

_ (1962): Cine español. Barcelona: Ediciones Rialp.

GARCÍA RIERA, Emilio (1969): Historia documental del cine mexicano: Época sonora. 1945/1948. México: Era. GARCÍA RUIZ, Víctor; TORRES NEBRERA, Gregorio (2003): Historia y antología del teatro español de posguerra (1940-1945). Madrid: Fundamentos.

GOBLE, Alan (1999): The Complete Index to literary sources in film. Londres: Bowker-Saur.

GÓMEZ MESA, Luis (1977): La literatura española en el cine nacional. Madrid: Filmoteca Nacional.

GREGORI, Antonio (2009): El cine español según sus directores. Madrid: Cátedra.

JIMÉNEZ MADRID, Ramón (1987): El Instituto Alfonso X el Sabio: 150 años de historia. Murcia: Tres Fronteras.

MARTÍNEZ MONTALBÁN, José Luis (2002): La novela semanal cinematográfica. Madrid: Consejo Superior de Investigaciones Científicas.

MESONERO ROMANOS, Ramón (2008): Memorias de un setentón, natural y vecino de Madrid. Tomo II. Barcelona: Crítica.

PEERS, Edgar Allison (1967): Historia del movimiento romántico español. Tomo II. Madrid: Gredos.

PÉREZ BOWIE, José Antonio (2008): Leer el cine. La teoría literaria en la teoría cinematográfica . Salamanca: Ediciones Universidad Salamanca.

PORTER I MOIX, Miquel (1985): Adrià Gual i el cinema primitiu de Catalunya, 1897-1916. Barcelona:

Publicacions i Edicions de la Universitat de Barcelona.

POZO ARENAS, Santiago (1984): La industria del cine en España: legislación y aspectos económicos, 18961970. Barcelona: Edicions Universitat de Barcelona. 
RIAMBAU, Esteve y TORREIRO, Casimiro (2008): Productores en el cine español. Estado, dependencias y mercado. Madrid: Cátedra/Filmoteca Española.

ROMERA CASTILLO, José (2013): Teatro Español. Siglos XVIII-XXI. Madrid: Universidad Nacional de Educación a Distancia.

SOLOMON, Aubrey (2011): The Fox Film Corporation, 1915-1935: A History and Filmography . Jefferson: McFarland.

ULRICH, Paul, S.; DAHLBERG, Gunilla; FASSEL, Horst (2016): Im Spiegel der Theatergeschichte. Berlín: Lit Verlag

(01) $A B C, 4$ de abril de 1923 (sin firma).

(02) $A B C, 30$ de diciembre de 1924 (sin firma).

(03) http://www.imdb.com/title/tt0005071/?ref_=fn_al_tt_1

(04) http://memory.loc.gov/diglib/ihas/loc.mbrs.sfdb.10835/default.html

(05) New York Times, 19 de Julio de 1920 (sin firma): «Some of the separate scenes are effectively staged. Other scenes, however, are weak, and the treatment of the story as a whole leaves it, despite its good points, extremely tedious in many places. The central action is psychological - the working of ugly gossip on the minds of three innocent people - and this should have had imaginative, suggestive, perhaps symbolical treatment. But the pictures are literal, simply animated photographs of externals, and subtitles are depended upon for psychological analysis - something of which they are incapable. The result is lack of force, failure to convince».

(06) http://memory.loc.gov/diglib/ihas/loc.mbrs.sfdb.7129/default.html

(07) http://www.silentsaregolden.com/arnemetromgm.html

(08) En las páginas de The American Film Institute Catalog of Motion Pictures produced in the United States, vol. II (1921-1930), P. 461, aparecen indistintamente los nombres de José y Felicia como Ernesto y Teodora para referirse a los mismos personajes.

(09) HALL, Mordaunt en New York Times, 19 de abril de 1927: «John M. Stahl has produce an absorbing picture, and although its plot has no great depth, the narrative flows so easily and convincingly that it is a joyous relief after the many pictures overflowing with artificialities».

(10) La Vanguardia, 5 de mayo de 1927 (sin firma).

(11) Todos los extractos de informes de este párrafo, firmados el 23 de julio de 1951, están contenidos en A.G.A.M.C. $36 / 03407$.

(12) Primer Plano, n 575, 21 de octubre de 1951.

(13) Entendemos que Gómez Tello no había leído El gran galeoto, porque dicho episodio no se contiene en la obra de José Echegaray - a no ser que en su crítica se refiriera, caso improbable, a Alfredo Echegaray, arrogándole, de esta forma, toda la responsabilidad -. Elude, de esta forma, la responsabilidad del director, como si éste no hubiera podido prescindir, de haberlo deseado, de dicha escena.

(14) $A B C, 25$ de noviembre de 1951. Edición de Andalucía.

(15) Ecclesia n 536. 20 de octubre de 1951, p. 22.

(16) Informe de José Luis García Velasco de 5 de noviembre de 1950 contenido en A.G.A.M.C. 36/04721. 
(17) Ibídem.

(18) Informe de Fray Mauricio de Begoña de 8 de noviembre de 1950 contenido en A.G.A.M.C. 36/04721.

(19) Informe de Fermín del Amo de 8 de noviembre de 1950 contenido en A.G.A.M.C. 36/04721.

(20) Informe de Bartolomé Mostaza de 16 de octubre de 1950 contenido en A.G.A.M.C. 36/04721.

(21) Informe de Fermín del Amo de 8 de noviembre de 1950 contenido en A.G.A.M.C. 36/04721.

(22) Informe de Fray Mauricio de Begoña de 8 de noviembre de 1950 contenido en A.G.A.M.C. 36/04721.

(23) Informe de José Luis García Velasco de 5 de noviembre de 1950 contenido en A.G.A.M.C. 36/04721.

\section{BREVE SEMBLANZA DEL AUTOR}

Juan Ignacio Valenzuela Moreno. Bilbao (Vizcaya) (1975). Licenciado en Derecho y en Ciencias del Trabajo por la Universidad de Córdoba y actualmente realizando el Doctorado sobre la obra de Rafael Gil. Ha publicado en Fonseca (2015) y presentado comunicación en Congreso Internacional de Barcelona sobre Documental y Memoria Histórica (2014). Coautor del libro Cómo crear una película. Anatomía de una profesión (2008, T\&B Editores).

Ámbitos. Revista Internacional de Comunicación, n.33, edición de verano, 2016.

Recibido: 01/06/2016

Aprobado: 15/06/2016 